\title{
Double blind, placebo controlled trial of the remission inducing and steroid sparing properties of an ICAM-1 antisense oligodeoxynucleotide, alicaforsen (ISIS 2302), in active steroid dependent Crohn's disease
}

\author{
B R Yacyshyn, W Y Chey, J Goff, B Salzberg, R Baerg, A L Buchman, J Tami, R Yu, \\ E Gibiansky, W R Shanahan, the ISIS 2302-CS9 Investigators
}

See end of article for authors' affiliations

Correspondence to: Dr B R Yacyshyn, Division of Gastroenterology,

University of Alberta, Suite 2E3. 11 Walter Mackenzie Centre, 8440-1 12 St,

Edmonton, AB T6G 2R7

Canada;

bruce.yacyshyn@ualberta.ca www.gut.ca

Accepted for publication 6 November 2001
Background and aims: To evaluate the safety and efficacy of the intercellular adhesion molecule 1 (ICAM-1) antisense phosphorothioate oligonucleotide alicaforsen (ISIS 2302) in Crohn's disease. Methods: Active (Crohn's disease activity index (CDAl) 200-350), steroid dependent (prednisone 10-40 mg) Crohn's patients were randomised into three treatment groups: placebo versus ISIS 2302 (2 mg/kg intravenously three times a week) for two or four weeks. Patients were treated in months 1 and 3, with steroid withdrawal attempted by week 10. The primary end point (steroid free remission) was a CDAl $<150$ off steroids at the end of week 14 .

Results: A total of 299 patients were enrolled, with a mean baseline CDAl of 276 and steroid dose of $23 \mathrm{mg} /$ day. Rates of steroid free remission were equivalent for the two and four week ISIS 2302 groups $(20.2 \%$ and $21.2 \%)$ and the placebo group (18.8\%). At week 14 , steroid withdrawal was successful in more ISIS 2302 patients compared with placebo treated patients (78\% v 64\%; $\mathrm{p}=0.032$ ). Steroid free remission was highly correlated with exposure $(p=0.0064)$. Other clinical responses were correlated with exposure, with significant results versus placebo being observed in the highest area under the curve subgroup. CDAl scores decreased by 136 (112) at week 14 versus 52 (107) for placebo $(p=0.027)$ and inflammatory bowel disease score questionnaire improved by $43(31)$ versus 15 (36) for placebo $(p=0.027)$.

Conclusions: Although the primary outcomes failed to demonstrate efficacy, pharmacodynamic modelling suggests that alicaforsen (ISIS 2302) may be an effective therapy for steroid dependent Crohn's disease.
C rohn's disease is an inflammatory disease of the intestine, characterised by immune dysregulation and leucocyte recruitment into gastrointestinal tissue. ${ }^{1}$ Recent approaches to disrupting or influencing this inflammatory cascade have involved inflammatory cytokines, such as tumour necrosis factor (TNF- $\alpha$ ) and interleukin 10, and more recently cellular adhesion molecules. The diverse adhesion molecule group is responsible for cell "rolling", "sticking", and leucocyte migration through vascular endothelium at inflammatory sites. ${ }^{2}$ Specifically for intercellular adhesion molecule 1 (ICAM-1), there is minimal expression in normal ileal tissue. ${ }^{3}$

ICAM-1 (CD54), a member of the immunoglobulin superfamily, is constitutively expressed at low levels on vascular endothelial cells and leucocytes, including antigen presenting cells. ${ }^{4-6}$ In response to proinflammatory stimulators, including TNF- $\alpha$, many cells upregulate ICAM-1 surface expression. $^{78}$ ICAM-1 expression in Crohn's disease is increased in the ileum, ${ }^{3}$ apical colonic epithelium and local leucocytes, ${ }^{910}$ colonic vessel endothelium, ${ }^{9-11}$ colonic fibroblasts displaying enhanced T lymphocyte adhesion, ${ }^{12}$ lamina propria mononuclear cells, ${ }^{13}$ Peyer's patch cells, ${ }^{14}$ and peripheral blood monocytes. ${ }^{15}$ Tissue expression of ICAM-1 correlates with disease activity. ${ }^{16} \mathrm{An}$ anti-ICAM-1 therapeutic effect was effective in rheumatoid arthritis and psoriasis. ${ }^{17-20}$

ISIS 2302 is a 20 base phosphorothioate oligodeoxynucleotide designed to hybridise in the $3^{\prime}$ untranslated region of human ICAM-1 mRNA. ${ }^{21}$ The heterodimer formed by ISIS 2302 and mRNA is a substrate for RNase $\mathrm{H}$, a family of ubiquitous enzymes that cleave RNA in DNA-RNA heterodimers. ${ }^{22}$
Treatment with ISIS 2302 in vitro results in a highly specific reduction in ICAM-1 mRNA and consequently markedly lowers ICAM-1 protein expression. ${ }^{21}{ }^{23-26}$ Murine and rat analogues of ISIS 2302 have been effective in multiple animal models of colitis, inflammatory diseases, and organ transplantation. ${ }^{27-29}$

A study in normal volunteers demonstrated excellent ISIS 2302 tolerability infused intravenously over two hours every other day for four doses. ${ }^{30}$ These subjects received doses of up to $2 \mathrm{mg} / \mathrm{kg}$, and experienced a clinically silent dose-responsive transient increase in activated partial thromboplastin time (aPTT) and complement split product C3a (but not C5a). ${ }^{31}{ }^{32} \mathrm{~A}$ pilot study evaluated 20 subjects with moderately active Crohn's disease on corticosteroids, with or without aminosalicylates, receiving ISIS 2302 at doses of $0.5-2 \mathrm{mg} / \mathrm{kg} /$ day intravenously 13 times over four weeks. This study suggested durable remission inducing and steroid sparing qualities for ISIS 2302 in Crohn's subjects, with an excellent safety profile. ${ }^{33}$ A recently reported incomplete study of subcutaneous antisense to ICAM-1 was ineffective at a low dose of $0.5 \mathrm{mg} / \mathrm{kg}$ administered five days per week for up to four weeks ${ }^{34}$ with local and systemic intolerance, ${ }^{35}$ and was terminated at its mid point.

Abbreviations: aPTT, activated partial thromboplastin time; AUC, area under the curve; $\mathrm{CDAl}$, Crohn's disease activity index; $\mathrm{C}_{\max }$ maximum concentration; IBDQ, inflammatory bowel disease questionnaire; ICAM, intercellular adhesion molecule; PK, population pharmacokinetics; sICAM, soluble ICAM-1; TNF, tumour necrosis factor. 
ISIS 2302-CS9 pivotal IV Crohn's trial

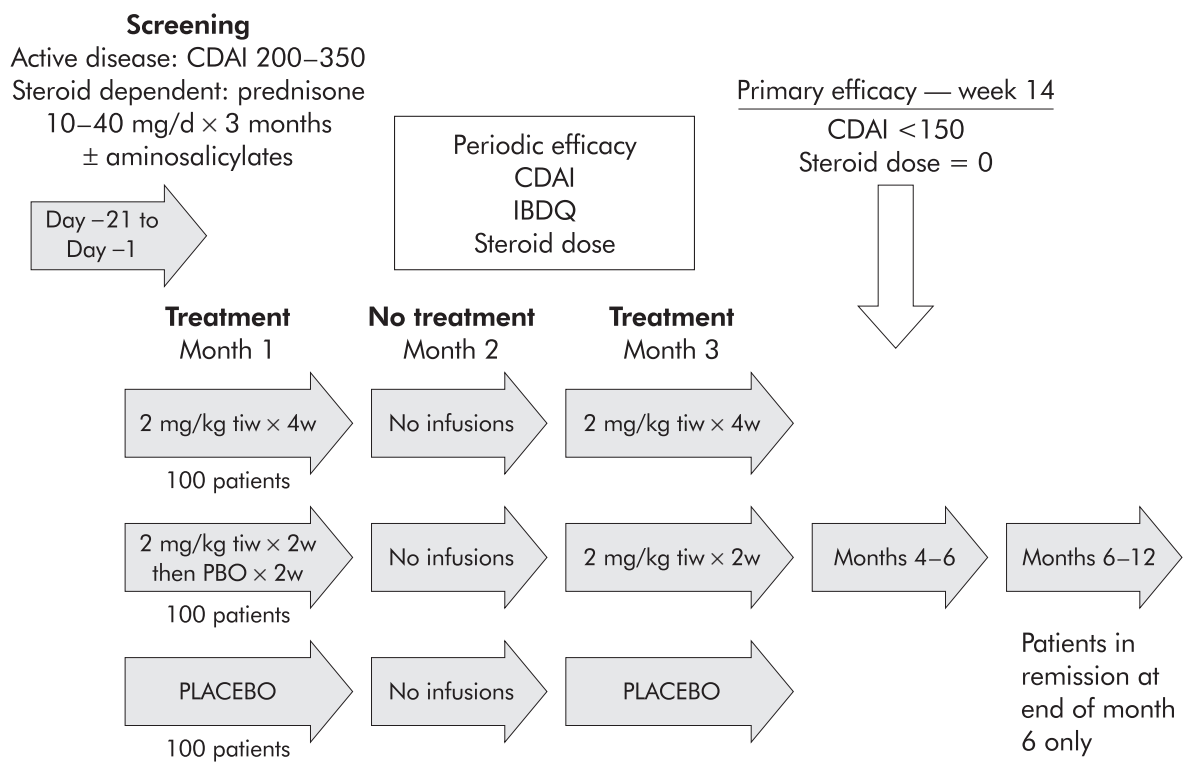

Figure 1 Study plan. Patients were prospectively evaluated during screening, and treatment was administered three times a week (tiw) for two or four weeks after randomisation. Patients were followed for an additional six or 12 months. Patients were stratified by baseline corticosteroid dose (low dose 10-19 mg/day; high dose $20-40 \mathrm{mg} /$ day) and then tapered as follows. High dose stratum: $20 \mathrm{mg} / \mathrm{day}$ at day 8 , then tapered by $2.5 \mathrm{mg} /$ week beginning on day 15; low dose stratum: maintain baseline dosage and then taper by $2.5 \mathrm{mg} /$ week to maintain dosage by study week with high dose stratum. CDAl, Crohn's disease activity index; IBDQ, inflammatory bowel disease questionnaire.

\section{METHODS}

\section{Patients}

Patients aged 14-80 years were enrolled with moderately active (Crohn's disease activity index (CDAI) 200-350), steroid dependent Crohn's disease (active disease for $\geqslant 3$ previous months despite 10-40 mg of prednisone or equivalent, with at least one unsuccessful taper attempt), documented within the previous two years and at study onset. Patients or their guardians signed institutionally approved consent forms, and institutional ethics review boards approved all protocols. Minors also provided written assent. Corticosteroids were stable for at least the two weeks prior to study entry. Patients were allowed stable doses of aminosalicylates but immunosuppressives were excluded in the prior four weeks.

\section{Randomisation}

Patients were stratified by their baseline steroid dose (prednisone equivalent of $10-19$ or 20-40 mg/day) for randomisation (fig 1). This protocol is based on pilot studies and the North American Methotrexate Study. ${ }^{30} 33$ Randomisation consisted of placebo or one of two ISIS 2302 regimens, administered at $2 \mathrm{mg} / \mathrm{kg}$ intravenously three times a week for two weeks or four weeks. Infusions were administered over two hours and saline was used for placebo infusions. Two treatment courses were administered, in months 1 and 3. The maximum permitted dosage was $200 \mathrm{mg}$; a few patients weighing $>100 \mathrm{~kg}$ were administered somewhat less than $2 \mathrm{mg} / \mathrm{kg}$.

\section{Corticosteroid taper}

Patients in the high dose corticosteroid stratum maintained their baseline dosage until day 8 , at which time they initiated prednisone $20 \mathrm{mg} /$ day, and then were tapered as tolerated by $2.5 \mathrm{mg}$ /day per week. Patients in the low dose stratum maintained their baseline dosage until the protocol day on which a high dose patient would be tapered to a lower dose (fig 1). The low dose stratum patients then tapered at $2.5 \mathrm{mg}$ /day per week as tolerated, so one patient could be weaned from corticosteroids by the beginning of week 10 .

\section{Efficacy assessments}

The primary end point was corticosteroid free remission (CDAI $<150$, corticosteroid dose $=0$ ) at week 14. Other secondary end points included corticosteroid utilisation and quality of life, assessed by the inflammatory bowel disease questionnaire (IBDQ). Additional response levels included low dose steroid dependent remission (CDAI $<150$, corticosteroid dose $\leqslant 10 \mathrm{mg}$ per day), remission (CDAI $<150$, corticosteroid dosage $\leqslant$ baseline level), response $(>100$ point decrease in CDAI with corticosteroids sbaseline dose), and partial response ( $>70$ point decrease in CDAI with corticosteroids $\leqslant$ baseline dose). Patients in remission at month 6 were followed for an additional six months. Investigators were blinded for 12 months and Isis personnel for six months after data had been collected and the database locked.

\section{Laboratory investigations}

All routine laboratory analyses were performed at Covance (Indianapolis, Indiana, USA). Soluble ICAM-1 (sICAM-1) levels were measured in the laboratory of Robert Rothlein PhD (Boehringer Ingelheim Pharmaceuticals, Inc., Ridgefield, CT, USA) by ELISA, as previously described. ${ }^{37}$ In this assay, healthy blood donors record a mean control value of 191 (15) $\mathrm{ng} / \mathrm{ml}^{38}$ Anti-ISIS 2302 antibody levels were measured by ELISA (Covance, Vienna, Virginia, USA) using goat antihuman IgG and IgM peroxidase conjugated second antibodies (Cappel) for detection, and mouse monoclonal IgG anti-ISIS 2302 antibody (Harlan Bioproducts for Science, Indianapolis, Indiana, USA) as a positive control. Positive results were confirmed by adding blocking levels of free ISIS 2302.

As phosphorothioate oligonucleotides transiently prolong the aPTT, post infusion aPTT results could have unblinded the study. Investigators and ISIS personnel remained blinded to aPTT results throughout the trial.

\section{Pharmacokinetics}

As part of the prospective design of this study, plasma for ISIS 2302 concentrations was obtained at $0,2,3$, and 5 hours after the start of the study drug infusion on day 1 , and at the end of 
Table 1 Baseline demographic and disease characteristics

\begin{tabular}{|c|c|c|c|c|c|c|c|c|}
\hline & $\mathrm{n}$ & Age $(y)$ & $\operatorname{Sex}(M / F)$ & Disease duration (y) & CDAI & $\mathrm{CRP}(\mathrm{mg} / \mathrm{dl})$ & $\begin{array}{l}\mathrm{sICAM*}(\mathrm{ng} / \mathrm{ml}) \\
\text { (median (range)) }\end{array}$ & $\begin{array}{l}\text { Steroid dose } \\
\text { (mg/day) (median } \\
\text { (range) [\% in high } \\
\text { dose stratum]) }\end{array}$ \\
\hline \multicolumn{9}{|l|}{ ISIS 2302} \\
\hline 2 Week & 99 & 39.2 (12.9) & $36 / 63$ & 11.0 (10.7) [0.1-78.7] & $283.7(51.6)$ & $4.33(15.0)$ & $253(63-630)$ & $70(10-40)$ [62] \\
\hline 4 Week & 99 & 39.3 (11.9) & $36 / 63$ & 9.1 (7.4) [0.2-38.5] & $274.4(52.8)$ & $3.55(10.1)$ & $215(82-881)$ & $20(10-45)[61]$ \\
\hline $\begin{array}{l}\text { All ISIS } \\
2302\end{array}$ & 198 & $39.3(12.9)$ & $72 / 126$ & 10.1 (9.3) [0.1-78.7] & $279.1(52.3)$ & $3.95(12.8)$ & $230(63-881)$ & $20(10-45)[61]$ \\
\hline Placebo & 101 & $39.2(12.1)$ & $40 / 61$ & 9.8 (8.3) [1.0-50.4] & $269.3(54.2)$ & $2.46(6.3)$ & $234(71-784)$ & $20(10-55)[64]$ \\
\hline
\end{tabular}

infusion (two hours) on days 10 and 26, for each treatment cycle. Plasma concentrations of ISIS 2302 were determined by PPD Development (Richmond, Virginia, USA) using a previously validated capillary gel electrophoresis method. ${ }^{39}$

Population pharmacokinetic (PK) analysis was performed by GloboMax LLC (Hanover, Maryland, USA). The population PK approach allows the analysis of sparse pharmacokinetic data from a variety of unbalanced designs, yielding a mathematical model of drug behaviour. The model is used to describe and predict drug concentrations in plasma and obtain reliable estimates of overall drug exposure in the treated population..$^{41}$ The population analysis is a post hoc analysis to generate a new hypothesis, and this hypothesis is being used in a new trial. The population approach used in this study was to extract potentially useful pharmacokinetic/ pharmacodynamic information from a complex clinical trial.

A preliminary, one compartment, PK model was developed using NONMEM (Version V, Level 1.1; UCSF, San Francisco, California, USA). ${ }^{42}$ Sixteen demographic and laboratory covariate terms were screened for their effects on the preliminary model, including age, sex, height, weight, steroid dose, liver function, renal function, and $\mathrm{C} 3 \mathrm{a}$ and $\mathrm{C} 5 \mathrm{a}$ levels. The covariate model was built using stepwise addition and backward elimination procedures. ${ }^{4041}$

The model established in a sample population of $70 \%$ of the total number of patients (index data set) was tested against the remaining $30 \%$ of patients (validation data set). Bias and model predictions were evaluated in both the entire population and the population stratified by important covariates, using plots of predicted versus actual values and plots of random effects versus covariates.

\section{Pharmacodynamic analysis}

As one of the outcomes measured by design in this study, the relationship between efficacy and drug exposure was assessed using various statistical methods. Two measures of drug exposure per dose were computed for each ISIS 2302 treated patient: a predicted maximum concentration $\left(\mathrm{C}_{\max }\right)$ and a predicted area under the concentration-time curve (AUC). Correlation of patient drug exposure (AUC) with remission rates, change in CDAI, or change in IBDQ were analysed using logistic regression, linear regression, and descriptive statistics. ${ }^{40}$ To determine whether there were AUC thresholds above which response rates improved, patients were categorised by 15 $\mu \mathrm{g} \times \mathrm{h} / \mathrm{ml}$ AUC increments over the dose per exposure range (groups AUC $\leqslant 35,35.1-50,50.1-65$, and $>65 \mu \mathrm{g} \times \mathrm{h} / \mathrm{ml}$ ).

\section{Statistical analysis}

All patients randomised to receive treatment who received at least one intravenous infusion of ISIS 2302 were included in the efficacy analyses. The primary end point, steroid free remission (CDAI $<150$ off steroids) at week 14 was compared between treatment groups using the Cochran Armitage trend test, stratified by the baseline prednisone dose, which tests for trends in steroid free remission rates. The two week and four week cohorts were analysed individually and then combined as no differences were detected.

Secondary analyses included comparison of remission rates, response rates, mean values of CDAI over time, corticosteroid use over time, IBDQ over time, dropouts for disease progression or lack of efficacy, and duration of remission, using SAS (version 6.12) Windows NT Statistical package (Cary, North Carolina, USA). Binary end points were analysed using $\chi^{2}$ tests or Fisher's exact tests. Continuous end points were analysed using $t$ tests and log rank tests, and logistic regression analysis was used to correlate binary variables and continuous variables. By definition, patients remained in steroid free remission for CDAI fluctuations above 150 if the score returned to $<150$ at the next visit. The primary safety analysis for adverse events was coded using the COSTART dictionary.

\section{RESULTS}

Fifty three centres across Europe and North America randomised 299 patients, with 101 patients in the placebo arm and 99 patients each in the two week and four week ISIS 2302 arms. Patients in the three treatment groups were similar with respect to baseline characteristics (table 1). A history of previous anti-TNF monoclonal antibody use was reported in $5.7 \%$, the majority having discontinued this agent due to lack of effect. Interestingly, patients with prior use of immunosuppressives had lower response rates (14\%) than those without prior immunosuppressive use (26\%). Even in the subgroup of patients with a high AUC, only $40 \%$ (2/5) of patients with prior immunosuppressives achieved a response while $75 \%(3 / 4)$ of patients without prior immunosuppressives achieved a response.

Study completion rates for the six month trial were $59.1 \%$ for the ISIS 2302 treated patients and 52.5\% for the placebo patients (table 2); most withdrawals were for lack of efficacy or disease progression (26\% and 35\% for ISIS 2302 and placebo, respectively). Two placebo subjects (2\%) withdrew for adverse events (ulcer, recreational drug overdose). One patient in the two week ISIS 2302 arm died from myocardial infarction. Eight additional ISIS 2302 subjects (4\%) withdrew due to adverse events, including an ISIS 2302 drug reaction consisting of facial flushing, chest tightness, and dyspnoea during two infusions.

\section{Pharmacokinetics}

Pharmacokinetic data were collected for 181/199 ISIS 2302 treated patients. The $\mathrm{T}_{1 / 2}$ for ISIS 2302 was 1.11 ( 0.2$)$ hours and the average maximum concentration $\left(\mathrm{C}_{\max }\right)$ was 14.8 (3) $\mu \mathrm{g} / \mathrm{ml}$ (table 3). ISIS 2302 pharmacokinetics were well described by a one compartment linear model, and evaluation of the model demonstrated a good fit without evidence of bias.

The analysis identified two important covariates altering the pharmacokinetics of ISIS 2302: weight and sex (fig 2). The 
Table 2 Patient disposition (initial six months)

\begin{tabular}{|c|c|c|c|c|c|c|}
\hline & \multirow[b]{2}{*}{$\mathrm{n}$} & \multirow[b]{2}{*}{ Completed } & \multicolumn{4}{|c|}{ Discontinuations } \\
\hline & & & $\begin{array}{l}\text { Adverse } \\
\text { event }\end{array}$ & Death & $\begin{array}{l}\text { Lack of efficacy/ } \\
\text { disease progression }\end{array}$ & Othert \\
\hline \multicolumn{7}{|l|}{ ISIS 2302} \\
\hline 2 Week & 99 & 59 & 5 & 1 * & 20 & 14 \\
\hline 4 Week & 99 & 58 & 3 & 0 & 32 & 6 \\
\hline All ISIS 2302 & 198 & 117 & 8 & 1 * & 52 & 20 \\
\hline Placebo & 101 & 53 & 2 & 0 & 35 & 11 \\
\hline
\end{tabular}

Table 3 ISIS 2302 pharmacokinetics

\begin{tabular}{lcc}
\hline Pharmacokinetics & All ISIS 2302 & ISIS 2302 subset: \\
& $2 \mathrm{mg} / \mathrm{kg} / 2 \mathrm{~h}$ & AUC $>65 \mu \mathrm{g} \times \mathrm{h} / \mathrm{ml}$ \\
\hline $\mathrm{n}$ & 181 & 9 \\
$\mathrm{C}_{\max }(\mu \mathrm{g} / \mathrm{ml})$ & $14.83(3.06)$ & $22.53(2.48)$ \\
$\mathrm{T}_{1 / 2}(\mathrm{~h})$ & $1.11(0.19)$ & $1.55(0.22)$ \\
$\mathrm{AUC}(\mu \mathrm{g} \times \mathrm{h} / \mathrm{ml})$ & $42.46(12.22)$ & $76.15(10.0)$ \\
$\mathrm{CL}(\mathrm{ml} / \mathrm{min} / \mathrm{kg})$ & $0.85(0.24)$ & $0.44(0.055)$ \\
$\mathrm{V}_{\mathrm{d}}(\mathrm{ml} / \mathrm{kg})$ & $78.44(10.89)$ & $58.97(6.85)$
\end{tabular}

$\mathrm{C}_{\max }$, maximum concentration; $\mathrm{T}_{1 / 2}$, half life; $\mathrm{AUC}$, area under the curve; $\mathrm{Cl}$, clearance; $\mathrm{V}_{\mathrm{d}}$, volume of distribution.

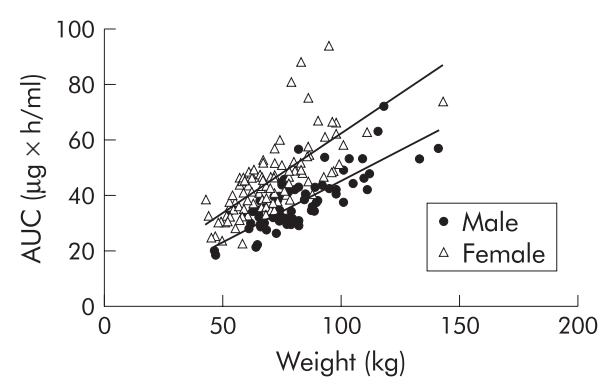

Figure 2 Average calculated ISIS 2302 drug exposure (area under the curve (AUC)) for individual patients following a $2 \mathrm{mg} / \mathrm{kg}$ dose, depicted as a function of weight in men $(n=66)$ and women $(n=115)$.

average drug exposure per dose (AUC) was 38.0 (10.2) $\mu g \times \mathrm{h} / \mathrm{ml}$ in men and 44.7 (12.7) $\mu g \times \mathrm{h} / \mathrm{ml}$ in women. For a constant weight of $70 \mathrm{~kg}$, the AUC and $\mathrm{C}_{\max }$ for females were higher than for males. For average study weights of $80 \mathrm{~kg}$ (males) and $67 \mathrm{~kg}$ (females), there was a trend towards an increased AUC in females.

The effects of sex on drug exposure were primarily mediated through effects on drug clearance rates. Plasma clearance was $37 \%$ higher in males, resulting in a shorter $\mathrm{T}_{1 / 2}$ of 0.94 for $70 \mathrm{~kg}$ males versus 1.14 hours for $70 \mathrm{~kg}$ females. The volume of distribution was also sex dependent, explained partially by differences in body fat composition as ISIS 2302 has limited uptake by adipose tissue. ${ }^{32}$ Metabolism was not affected by sex or exogenous oestrogen use.

\section{Corticosteroid use and Crohn's disease response}

Of the 191 patients completing week 14, only 64\% (40/63) on placebo had successfully discontinued steroids compared with $78 \%(100 / 128)$ for the ISIS 2302 treated groups $(p=0.032)$. Cumulative steroid use through week 14 did not differ among the intent to treat cohorts but was clearly lower for steroid free remitters $(p<0.001)$. Similar proportions of patients in the three treatment groups achieved the primary end point of steroid free remission at the end of week 14: $19.2 \%$ in the two week group, $21.2 \%$ in the four week group $(20.2 \%$ for the combined ISIS 2302 groups), and $18.8 \%$ of placebo treated patients. Rates of remission (steroid free, low dose steroid dependent, and steroids s baseline) and response (response and partial response) over time were similar between treatment arms at various time points throughout the trial. Mean values for CDAI over time, steroid dose over time, duration of disease, prior immunosuppressive use, and IBDQ over time were similar between the three treatment groups (not shown). Baseline steroid use predicted steroid free remission, with remitters having an average corticosteroid dose of 19.0 (8.0) $\mathrm{mg} /$ day at baseline and non-remitters starting at 23.5 (10.8) mg/day $(\mathrm{p}<0.005)$.

\section{Pharmacodynamics}

There was a strong correlation between drug exposure and response to ISIS 2302 treatment. Following the $2 \mathrm{mg} / \mathrm{kg}$ intravenous ISIS 2302 dose, plasma AUC levels ranged from 13.49 to $96.09 \mathrm{\mu g} \times \mathrm{h} / \mathrm{ml}$ although all patients received the same $2 \mathrm{mg} / \mathrm{kg}$ dosage. For analysis, the AUC range was divided into 15 $\mu \mathrm{g} \times \mathrm{h} / \mathrm{ml}$ dose increment groups: $\leqslant 35(\mathrm{n}=54) \mu \mathrm{g} \times \mathrm{h} / \mathrm{ml} ; 35.1-50$ $\mu \mathrm{g} \times \mathrm{h} / \mathrm{ml}(\mathrm{n}=90) ; 50.1-65 \mu \mathrm{g} \times \mathrm{h} / \mathrm{ml}(\mathrm{n}=28) ;$ and $>65 \mu \mathrm{g} \times \mathrm{h} / \mathrm{ml}$ $(n=9)$. Although the number of patients in the higher exposure groups was small, steroid free remission rates increased as AUC increased. Remissions rose from $13.0 \%$ (7/54) for the lowest AUC subgroup to $21.4 \%(6 / 28)$ for those in the AUC 50.1-65 $\mu \mathrm{g} \times \mathrm{h} / \mathrm{ml}$ subgroup, and $55.6 \%$ (5/9) for the highest AUC subgroup ( $\mathrm{p}=0.023$ for the highest AUC subgroup $v$ placebo). Logistic regression of steroid free remission rates as a function of AUC demonstrated significant trends $(p=0.0064)$.

Other measures of clinical response consistently demonstrated improvement for the highest AUC subgroup. The same strong correlation between drug exposure and secondary disease response measures was observed for changes in CDAI and IBDQ (fig 3A, B) at the end of week 14, both showing statistically significant improvements compared with placebo $(p<0.03)$. Correlation of CDAI improvement at week 14 and AUC confirmed this significant association $(\mathrm{p}=0.02)$.

The highest AUC subgroup (>65 $\mu \mathrm{g} \times \mathrm{h} / \mathrm{ml}$ ) were predominantly female (8/9), Caucasian (8/9), and had relatively high obesity indices (average weight $98.6 \mathrm{~kg}$ ), resulting in slower clearance and higher plasma levels, necessary to achieve a 

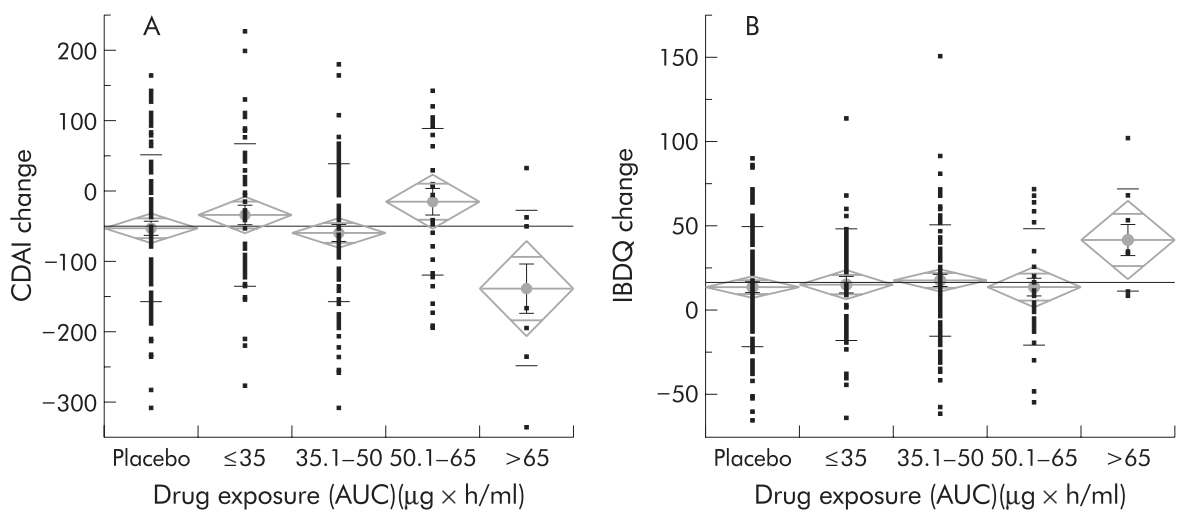

Figure 3 Change in Crohn's disease activity index (CDAI) (A) and inflammatory bowel disease questionnaire (IBDQ) (B) scores at week 14, stratified by area under the curve (AUC) into four cohorts. The diamond shapes indicate the $95 \%$ confidence intervals and the bars signify 1 or 2 SDs. CDAl and IBDQ significantly improved for the high AUC subgroup versus placebo ( $p=0.027$ for both).

higher drug exposure level. The highest AUC patients achieving steroid free remission $(n=5)$ had a trend towards lower baseline steroid doses compared with those who did not achieve this end point $(\mathrm{n}=4)$ ( 16.5 and $21.9 \mathrm{mg} /$ day; NS).

\section{Duration of remission}

Time to steroid free remission was similar across the three treatment groups. For patients who reached steroid free remission (within the six month protocol), mean (SD) time to first day of steroid free remission was 85.3 (35.9) days for placebo, 78.3 (22.0) days for the two week cohort, and 82.5 (29.0) days for the four week cohort. The one year follow up response duration was completed by 34 (17\%) ISIS 2302 and 16 (18.8\%) placebo patients from a potential pool of $40(20.2 \%)$ ISIS 2302 and $19(18.8 \%)$ placebo patients in steroid free remission at month 6 .

\section{Laboratory assessments and safety}

Of 91 patients studied, one male subject developed new antiISIS $2302 \mathrm{IgG} / \operatorname{IgM}$ antibody by day 82 at a 1:10 titre without clinical sequelae. ISIS 2302 was well tolerated (table 4). Medically important adverse events were limited to hypersensitivity reactions in a small proportion of patients $(2 \%)$. As anticipated, transient aPTT increases without bleeding sequelae, and transient facial flushing or a feeling of warmth during infusion, were also noted $(11.6 \%$ of drug treated, $4 \%$ of placebo treated patients; $\mathrm{p}=0.03$ ).

\section{DISCUSSION}

The use of antisense molecules to target disease causing proteins such as ICAM- 1 is in the early stages of development. A previously published pilot study of antisense to ICAM-1 (ISIS 2302) suggested that $0.5-2 \mathrm{mg} / \mathrm{kg}$ three times a week is an effective intravenous dose range in Crohn's disease.

The proportion of patients achieving primary and secondary end points in this trial were similar over time, suggesting that ISIS 2302 at the dose and schedule employed in this protocol is ineffective in Crohn's patients. By using population pharmacokinetics (PK) as a prior component of this study design to model drug exposure in each patient, a broad range (fivefold) in drug exposure per dose (AUC) showed a significant relationship between drug exposure and response. This suggests that ISIS 2302 may be effective when given in adequate doses. Failure to find a significant treatment effect in this study may be due to insufficient dosing of patients. Such an inference must be tempered as it is based on retrospective analysis using pharmacodynamic modelling.

Our patients experienced a fivefold range of drug exposure per dose (13.49-96.09 $\mu \mathrm{g} \times \mathrm{h} / \mathrm{ml}$ ), although all patients received a dose of $2 \mathrm{mg} / \mathrm{kg}$. AUC per dose correlated significantly with rates of steroid free remission at the end of week 14, a primary study end point $(p=0.0064)$. Other measures of clinical response consistently demonstrated improvement for the highest AUC subgroup. The same strong correlation between drug exposure and secondary disease response measures was

\begin{tabular}{|c|c|c|c|c|c|c|}
\hline \multirow[b]{2}{*}{ Vasodilation } & \multicolumn{2}{|c|}{ Placebo $(n=101)$} & \multicolumn{2}{|c|}{$\begin{array}{l}\text { ISIS } 2302 \\
2 \mathrm{mg} / \mathrm{kg}(\mathrm{n}=198)\end{array}$} & \multicolumn{2}{|c|}{$\begin{array}{l}\text { ISIS } 2302 \text { subset: } \\
\text { AUC }>65 \mu \mathrm{g} \times \mathrm{h} / \mathrm{ml}(\mathrm{n}=9)\end{array}$} \\
\hline & 4 & $(4.0)$ & 23 & $(11.6)^{*}$ & 1 & (11.1) \\
\hline Rash & 15 & (14.9) & 19 & (9.6) & 0 & \\
\hline Urticaria & 0 & & 6 & (3.0) & 0 & \\
\hline Anaphylactoid reaction & 0 & & 2 & (1.0) & 0 & \\
\hline Myocardial infarction & 0 & & 1 & (0.5) & 0 & \\
\hline Schwannoma & 0 & & 1 & (0.5) & 0 & \\
\hline Asthenia & 22 & $(21.8)$ & 45 & $(22.7)$ & 0 & \\
\hline Flu syndrome & 12 & (11.9) & 27 & (13.6) & 1 & $(11.1)$ \\
\hline Headache & 26 & $(25.7)$ & 65 & (32.8) & 1 & (11.1) \\
\hline Dizziness & 16 & $(15.8)$ & 36 & $(18.2)$ & 1 & (11.1) \\
\hline Infection & 37 & (36.6) & 88 & (44.4) & 3 & (33.3) \\
\hline Pancreatitis & 1 & (1.0) & 0 & & 0 & \\
\hline Enterocolitis & 26 & (25.7) & 44 & (22.2) & 2 & (22.2) \\
\hline Nausea & 29 & $(28.7)$ & 49 & $(24.7)$ & 4 & (44.4) \\
\hline Vomiting & & (11.9) & 28 & (14.1) & 2 & (22.2) \\
\hline Abdominal pain & 16 & $(15.8)$ & 30 & (15.2) & 2 & $(22.2)$ \\
\hline Average post infusion aPTT increase (s) & & $8(4.66)$ & & $6(7.29)^{* *}$ & & $0(7.40)$ * * \\
\hline Maximum post infusion aPTT value (s) & 30. & $4(7.6)$ & 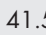 & $(7.4)^{* *}$ & 42 . & $(4.4)^{* *}$ \\
\hline
\end{tabular}

${ }^{*} p=0.03,{ }^{*} p<0.0001$ versus placebo. 
observed for changes in CDAI and IBDQ at the end of week 14, both showing significant improvements versus placebo $(p<0.03)$. Correlation of CDAI improvement at week 14 and AUC confirmed this significant association $(p=0.02)$. Patients with a higher exposure per dose had remissions of longer duration but the trend was not significant. This study demonstrated that a per kilogram dosing approach does not provide equal exposure to ISIS 2302, and clarified the pharmacokinetics of ISIS 2302 not detected in the smaller pilot study. ${ }^{33}$

Overall, steroid free remission, our primary end point, was strongly related to ISIS 2302 drug exposure. The observation of an increased remission rate was significantly limited by the small number of patients receiving adequate exposure but was strengthened by the additional significant correlations between increasing drug exposure and improvements in both CDAI and IBDQ. In addition, steroid withdrawal at week 14 was more successful for ISIS 2302 recipients versus placebo subjects $(\mathrm{p}=0.032)$.

A significantly greater proportion of ISIS 2302 treated women $(24.6 \%)$ than men $(12.5 \%)$ achieved the primary end point $(p=0.04)$; however, neither was statistically different from placebo. The higher response rate in women appears to be primarily due to higher drug exposure in women. A trend towards higher remission rates was noted in women receiving exogenous oestrogens which may reflect in vitro data demonstrating that oestrogen and progesterone, but not testosterone, enhance ICAM- 1 induction on TNF- $\alpha$ stimulated endothelial cells. ${ }^{43}$

These data suggest that ISIS 2302 may be effective therapy for steroid dependent Crohn's disease, with steroid sparing and remission inducing properties, when drug exposure is adequate. Although the current study could be construed as a failure, the AUC findings and the response of a subgroup of patients may represent a significant breakthrough in our understanding of this new class of drugs. Potentially, failure to detect an overall significant treatment effect in this study was due to insufficient dosing of patients, but paired with no dose limiting toxicity. This supports evaluation of higher doses of ISIS 2302 in Crohn's disease, which is currently underway.

\section{ACKNOWLEDGEMENT}

The authors would like to acknowledge Dr K Lea Sewell for valued comments.

\section{Authors' affiliations}

B R Yacyshyn, University of Alberta, Edmonton, Alberta, Canada W Y Chey, University of Rochester, Rochester, New York, USA

J Goff, Western States Clinical Research, Arvada, Colorado, USA

B Salzberg, Atlanta Gastroenterology Association, Atlanta, Georgia, USA

R Baerg, Tacoma Digestive Center, Tacoma, Washington, USA

A L Buchman, University of Texas, Houston, Texas, USA

J Tami, R Yu, W R Shanahan, Isis Pharmaceuticals, Carlsbad, California, USA

E Gibiansky, GloboMax LLC, Hanover, Maryland, USA

ISIS 2302-CS9 Investigators: F Anderson, G Koval, C Barish, M Safdi, D Taniguchi, L Sutherland, P Rutgeerts, W Depew, R Pruitt, S Hanaver, B Winston, B Dolin, W Koltun, R McCabe, J Scholmerich, S Van Deventer, G Wild, J Breiter, R Burakoff, J Deren, J Linne, M Regueiro, H Schwartz, B Shivakumar, D Binion, C Cattano, J Colombel, S Galandiuk, J Katz, V Rustgi, C Springgate, G Varilek, D Dalke, L Herzog, M Lamet, D Pambianco, J Singleton, E Torres, H Van Dullemen, R Baldassano, $F$ Cortese, D James, P Moses, A Raedler, D Riff, D Stanton, S Wilkofsky

Conflict of interest: B Yacyshyn is a medical advisor for ISIS pharmaceuticals. W R Shanahan, R Yu, and J Tami, are current or past employees of ISIS pharmaceuticals, Carlsbad, California, USA.

\section{REFERENCES}

1 Levine DS. Clinical features and complications of Crohn's disease. In: Targan SR, Shanahan F, eds. Inflammatory bowel disease: from bench to bedside. Baltimore: Williams and Wilkins, 1993:296-316.

2 Springer TA. Traffic signals for lymphocyte recirculation and leukocyte migration: the multistep paradigm. Cell 1994;76:301-14.
3 Bernstein CN, Sargent M, Gallatin WM. Beta 2 integrin/ICAM expression in Crohn's disease. Clin Immunol Immunopathol 1998;86: 147-60.

4 Dustin ML, Rothlein R, Bhan AK, et al. Induction by IL-1 and interferon tissue distribution, biochemistry, and function of a natural adherence molecule (ICAM-1). J Immunol 1986;137:245-54.

5 Rothlein R, Dustin ML, Marlin SD, et al. A human intercellular adhesion molecule (ICAM-1) distinct from LFA-1. J Immunol 1986;137:1270-4.

6 Simmons D, Makgoba MW, Seed B. ICAM, an adhesion ligand of LFA-1, is homologous to the neural cell adhesion molecule NCAM. Nature 1988:331:624-7.

7 To SS, Newman PM, Hyland M, et al. Regulation of adhesion molecule expression by human synovial microvascular endothelial cells in vitro. Arthritis Rheum 1996;39:467-77.

8 Beutler BR. The role of tumor necrosis factor in health and disease. Arthritis Rheum 1999;26:16-21.

9 Vainer B, Nielsen $\mathrm{OH}$. Changed colonic profile of P-selectin, platelet-endothelial cell adhesion molecule-1 (PECAM-1), intercellular adhesion molecule-1 (ICAM-1), ICAM-2, and ICAM-3 in inflammatory bowel disease. Clin Exp Immunol 2000; 121:242-7.

10 Pooley N, Ghosh L, Sharon P. Up-regulation of E-selectin and ICAM-1 differs between Crohn's disease and ulcerative colitis. Dig Dis Sci 1995;40:219-25

11 Souza HS, Elia CC, Spencer J, et al. Expression of lymphocyte-endothelial receptor-ligand pairs, $\alpha 4 \beta 7 / M A d C A M-1$ and OX40/OX 40 ligand in the colon and jejunum of patients with inflammatory bowel disease. Gut 1999;45:856-63

12 Musso A, Condon TP, West GA, et al. Regulation of ICAM-1 mediated fibroblast-T cell reciprocal interaction: implications for modulation of gut inflammation. Gastroenterology 1999;117:546-56.

13 Yacyshyn BR, Lazarovits A, Tsai V, et al. Crohn's disease, ulcerative colitis, and normal intestinal lymphocytes express integrins in dissimilar patterns. Gastroenterology 1994;107:1364-71.

14 Von Andrian UH, Mackay CR. T cell function and migration: two sides of the same coin. N Engl J Med 2000;343:1020-34.

15 Liu ZX, Hiwatashi N, Noguchi M, et al. Increased expression of costimulatory molecules on peripheral blood monocytes in patients with Crohn's disease. Scand J Gastroenterol 1997;32:1241-6.

16 Vainer B, Nielsen OH, Horn T. Comparative studies of the colonic in situ expression of ICAM-1, -2 , and -3 , beta 2 integrins (LFA-1, Mac- 1 , and p 150, 95), and PECAM-1 in ulcerative colitis and Crohn's disease. Am Surg Pathol 2000;24:1115-24.

17 Kavanaugh AF, Davis LS, Schulze-Koops H, et al. A phase I/II open label study of the safety and efficacy of an anti-intercellular adhesion molecule 1 monoclonal antibody in early rheumatoid arthritis. $J$ Rheumatol 1996;23:1338-44.

18 Davis LS, Kavanaugh AF, Nichols LA, et al. Induction of persistent T cell hyporesponsiveness in vivo by monoclonal antibody to ICAM-1 in patients with rheumatoid arthritis. J Immunol 1995;154:3525-37.

19 Kavanaugh AF, Schulze-Koops H, Davis LS, et al. Repeat treatment of rheumatoid arthritis patients with a murine anti-intercellular adhesion molecule 1 monoclonal antibody. Arthritis Rheum 1997;40:849-53.

20 Gottlieb A, Krueger JG, Bright R, et al. Effects of administration of a single dose of a humanized monoclonal antibody to CDI la on the immunobiology and clinical activity of psoriasis. J Am Acad Dermatol 2000;42:428-35

21 Bennett CF, Condon TP, Grimm S, et al. Inhibition of endothelial cell leukocyte adhesion molecule expression with antisense oligonucleotides. J Immunol 1994;152:3530-41.

22 Chiang MY, Chan H, Zounes MA, et al. Antisense oligonucleotides inhibit intercellular adhesion molecule 1 expression by two distinct mechanisms. J Biol Chem 1991;226:18162-71.

23 Henry SP, Templin MV, Gillett N, et al. Correlation of toxicity and pharmacokinetic properties of a phosphorothioate oligonucleotide designed to inhibit ICAM-1. Toxicol Pathol 1999;27:95-100.

$24 \mathrm{Wu} \mathrm{H}$, Lima WF, Crooke ST. Properties of cloned and expressed human RNase H1. J Biol Chem 1999;274:28270-8.

25 Mielo ME, Bennett CF, Miller BE, et al. Enhanced metastatic ability of TNF- $\alpha$ treated malignant melanoma cells is reduced by intercellular adhesion molecule-1 (CD54) antisense oligonucleotides. Exp Cell Res 1994;214:231-41.

26 Nestle FO, Mitra RS, Bennett CF, et al. Cationic lipid is not required for uptake and selective inhibitory activity of ICAM-1 phosphorothioate antisense oligonucleotides in keratinocytes. J Invest Dermatol 1994; 103:569-75.

27 Stepkowski SM, Tu Y, Condon TP, et al. Blocking of heart allograft rejection by ICAM-1 antisense oligonucleotides alone or in combination with other immunosuppressive modalities. J Immunol 1994;153:533646.

28 Kumasaka T, Quinlan WM, Doyle NA, et al. The role of ICAM-1 in endotoxin-induced pneumonia evaluated using ICAM-1 antisense oligonucleotides, anti-ICAM-1 monoclonal antibodies, and ICAM-1 mutant mice. J Clin Invest 1996;97:2362-9.

29 Bennett CF, Kornbrust D, Henry S, et al. An ICAM-1 antisense oligonucleotide prevents and reverses dextran sulfate sodium-induced colitis in mice. J Pharmacol Exp Ther 1997;280:988-1000.

30 Glover J, Leeds JM, Mant TGK, et al. Phase I safety and pharmacokinetic profile of an intercellular adhesion molecule-1 antisense oligonucleotide (ISIS 2302). J Pharmacol Exp Ther 1997;282: $1173-80$

31 Sheehan JP, Lan HC. Phosphorothioate oligonucleotides inhibit the intrinsic tenase complex. Blood 1998;92:1617-25.

32 Henry SP, Giclas PC, Leeds J, et al. Activation of the alternative pathway of complement by a phosphorothioate oligonucleotide: potential mechanism of action. J Pharmacol Exp Ther 1997;281:810-16. 
33 Yacyshyn BR, Bowen-Yacyshyn MB, Jewell L, et al. A placebo-controlled trial of ICAM-1 antisense oligonucleotide in the treatment of Crohn's disease. Gastroenterology 1998;114:1133-42

34 Schreiber S, Nikolaus S, Malchow H, et al. Absence of efficacy of subcutaneous antisense ICAM-1 treatment of chronic active Crohn's disease. Gastroenterology 2001;120:1339-46.

35 Shanahan WR. Properties of ISIS 2302 in humans. In: Crooke ST, ed Handbook of experimental pharmacology, vol 131: antisense research and applications. New York: Springer-Verlag, 1998:499-524.

36 Feagan BG, Rochon J, Fedorak R, et al. Methotrexate for the treatment of Crohn's disease. N Engl J Med 1995;332:292-7.

37 Rothlein R, Mainolfi EA, Czajkowski $M$, et al. A form of circulating ICAM-1 in human serum. J Immunol 1991;147:3788-93.

38 Cush JJ, Rothlein R, Lindsley HB, et al. Increased levels of circulating intercellular adhesion molecule 1 in the sera of patients with rheumatoid arthritis. Arthritis Rheum 1993;36:1098-102.

39 Leeds JM, Graham M, Truong L, et al. Quantitation of phosphorothioate oligonucleotides in human plasma. Anal Biochem 1996;235:36-43.
40 Nedelman JR, Gibiansky E, Cramer J, et al. Multiple dose pharmacokinetics of a long half-life drug: contributions of mathematica modeling. Eur J Drug Metab Pharmacokinet 1997;2:179-84.

41 Nedelman JR, Karara AH, Chang CT, et al. Inferring systemic exposure from a pharmacokinetic screen: model-free and model-based approaches. Stat Med 1995;14:955-68.

42 Statistical Consultants, Inc. PCNONLIN and NONLIN84: Software for the statistical analysis of nonlinear models. Am Stat 1986;40:52.

43 Cid MC, Kleinman HK, Grant DS, et al. Estradiol enhances leukocyte binding to TNF-stimulated endothelial cells via an increase in TNF-induced adhesion molecules E-selectin, intercellular adhesion molecule-1, and vascular cell adhesion molecule type 1. J Clin Invest 1994;93:17-25.

44 Maksymowych W, Blackburn W, Hutchings E, et al. A pilot study of ISIS 2302, an antisense oligodeoxynucleotide, in patients with active rheumatoid arthritis. Arthritis Rheum 1999:42.599.

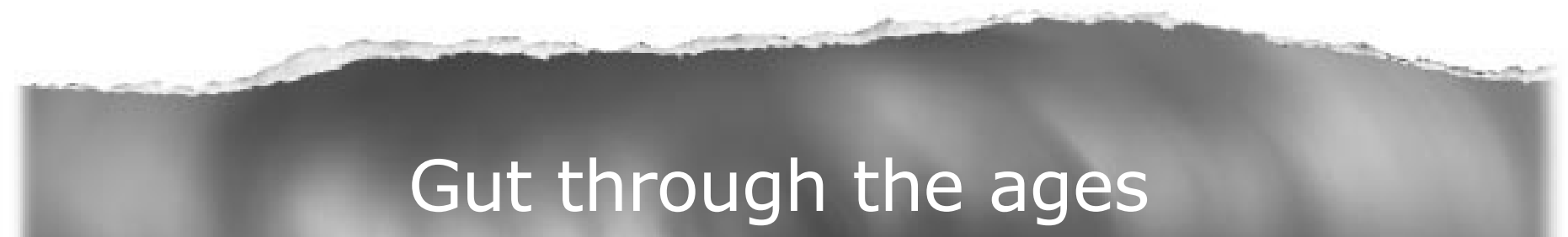

Browse the Archive

Gut online has an archive of content dating back to 1966 .

Full text from 1997; abstracts from 1975; table of contents from 1966

www.gutjnl.com 